\title{
State Responsibility for the Quality of Digital and Distance Education
}

\author{
Natalya Bobrova ${ }^{1, *}$ \\ ${ }^{1}$ Togliatti State University, Togliatti 445020, Russian Federation \\ *Corresponding author. Email: bobrovana@mail.ru
}

\begin{abstract}
\section{INTRODUCTION}

In today's Russia, highly fraught debate has developed around the problem of education digitalization and especially distances education. Until 2020, distance education was typical only for higher education. And in 2020, due to the pandemic, it also captured the field of school education: primary and secondary.
\end{abstract}

This article analyzes the opposing views of scientists on the problem of digital education and digitization in education. One can see that digitalization is accompanied by commercialization of education and other negative aspects related to the mental health of the younger generation. These aspects are highly controversial. Dialectical methods of paired categories are used: essences and manifestations, content and form, transfer quantity to quality, unity and the struggle of opposites, etc. The term "digital economy" contains a dialectical contradiction. On the one hand, the economy demands freedom of development and gravitates towards liberal-market methods, avoids administrative methods. On the other hand, transition to the digital economy is managed process, contributing to the country's transition to the new technological order. The purpose of the article is to analyze this contradiction and emerging problems. The arbiter of all disputes around education is the state. Only the state determines which way education will develop.

Keywords: Education, digital technology, distant learning, controversy, responsibility of the state.

Scientists and public figures recognize the progressiveness of digital education technologies. Without digital technologies, distance education itself would be impossible.

The variety of digital educational technologies, development of game educational methods contributes to the improvement of the educational process, especially in the context of distance education and the COVID-19 pandemic.

However, not all digital forms of education are equally capable of replacing the teacher adequately. Undoubtedly, the socialization of pupils also suffers, for there is nothing to replace live communication in the classroom. Pediatricians, psychologists, neurologists, sociologists and other scientists drew attention to the harm to the physical and mental health of schoolchildren that distance education brings: problems arise with memory, thinking consistency, identification, and socialization.

The literature has considered repeatedly the problems of education digitalization and science [1], as well as the reasons for devaluation of legal education
[2] and decline in the quality of higher education in general [3]. The commercialization of education, lack of competition for applicants of many universities and faculties, low quality of school education and, accordingly, decline in the quality of applicants, reduction of education itself to a vulgar service, decline in the prestige of teaching - this is the incomplete list of reasons for devaluation of education.

The term "digitalization" became the most fashionable trend in recent years [4]. The literature repeatedly noted the pros and cons of digitalization, including by the authors of the article [5].

\section{DISTANCE EDUCATION IN RUSSIA: AN AREA OF FURIOUS DEBATES}

Nowadays, in Russia, supporters of distance education have emerged, which striking symbol is the head of Sberbank, German Gref. The consistent opponent of distance education is Mikhalkov, the great Soviet and Russian director, actor, chairman of the Union of Cinematographers of Russia.

German Gref actively intervenes in education, science and culture. For the ideological justification of the bank's immense interference in education and other spheres of society's life, Sberbank was transformed in 2020 into the structure called SBER. "SBER" even sells food products via the Internet.

SBER, by financing the development of the 20202030 school education development program, actually privatized the country's future, because as the education of schoolchildren and their upbringing, so is the future. Since his school years, Gref hated school with its 
discipline and requirements. His dream is to destroy exams as such, replace them with game tests. He refers to the fact that $92 \%$ of schoolchildren in anonymous questionnaire answered that it is boring to study at school [6]. It is not explained how this data was obtained.

Gref believes that systemic education is necessary only for the elite of society - children from wealthy families, and the rest of the children should receive only skills suitable for future work. German Gref frankly admits that deep and systemic knowledge is not needed by the majority of the population; otherwise, such population will be difficult to control.

The population and especially young people need to be tamed to the "nipple" of the Internet, which will replace the need to remember and comprehend something. The population is a mindless mass of producers and consumers of services; it finds all the answers on the Internet. Such population is easy to control. Schoolchildren only need to be taught "soft skills" - communication, business conversation, quickly finding the right facts in the sea of information. And unclaimed school knowledge is forgotten instantly, only $15 \%$ remain in the memory. It is not explained where this figure is taken from [6].

Mikhalkov opposes the tendency to deafen the people and eliminate the educational function of education. In his BesogonTV show, he exposes the goals and methods of Russian liberals that infiltrated the Russian government. The word "besogon" is derived from the words "demons" (bes) and " exorcise" (gon). Mikhalkov exorcises liberal demons from education management. He states that the pandemic is excellent breeding ground for the destruction of traditional education: "The destruction follows from the Education2030 program. Here is the section "Death of Formats". According to this plan, the graduation diploma should die by 2025, and by 2035 (...) - the general education school, as well as the text (book, article) as the dominant form of knowledge transfer. The main thing is the book, the gigantic centuries-old culture of books publishing, the culture of reading books" [7].

In issue titled "Will Google Break the Spire of Moscow State University?" Mikhalkov traces the tendency of the society division into castes and layers [8]. Gref denies Mikhalkov's accusations and even claims that he has not seen this program. Although the specialists at Skolkovo, who developed the Education 2020-2030 program, admit that its development is funded by Gref, more precisely, by SBER company he heads. By the way, Gref's official salary is $15 \%$ of the entire profit of SBER [6], which amounted to 80 billion rubles in 2019.
Mikhalkov cites facts according to which the developers of the Education 2030 program are mostly foreign citizens or Russian specialists with dual citizenship. Thence, the natural question arises: what state do the developers of the Russian program of education serve?

\section{PROS AND CONS OF EDUCATION DIGITALIZATION}

Scientists express opposite points of view on the problem of education digitalization. For example, Professor Fatenkov has negative attitude to the theory and practice of digitalization and hears reproaches in his address: "You criticize, but you by yourself cannot do anything without a computer." But the professor's main argument is: "Take the computer away - I will not incur significant losses. This unit, really convenient (but what is the price of convenience?), I use it in three functions: as a typewriter, as a library, as mail.

If there will be no computers, I will return to the old means of printing and handwritten work (which I do not leave today), to the traditional forms of work. Of course, time will be wasted. But it will be spent on comprehension, because technologies spur, average and even destroy the individuality of the scientist. Saving time by no means guarantees qualitative, meaningful shifts in life and its understanding" [9].

The bustle and whipping up of the technological pace subjugate and typifies the nature of all our thoughts and actions. People often do not notice when an anomaly becomes the norm, since fashion becomes a drive and a motive for behavior, including in science. Just look, at first the word "modernization" was fashionable, now - "digitalization". Piles of literature (and "waste paper") were published on the topic of digitalization. According to Fatenkov, "endless deadlock arises - intensification of efforts to replicate standardized consumer goods" [9].

IT-technologies with their obsessive stereotyped servility regarding acceleration of the processes of transfer and receipt of information standardize imperceptibly a person himself (herself), because he (she) is offered something ready for use. They are not going to enrich us with meanings; we are treated with reduced fragments - information itself.

The worldview becomes eclectic, unsystematic, perfectly controlled from the outside. Consistency of thinking disappears, and often the thought itself. As it was said in one anecdote about a monkey, "what is to think about there - you just have to shake it!" The dream of the Russian Mephistopheles Gref is for the younger generation to be an excellent material for the 
ruling elite; therefore, the thinking of biorobots is formed, processed, according to Gref, by specially trained political scientists. The controlled mass should be able not to synthesize and receive the product of independent thinking, but to acquire the skills of combining typed workpieces. Gref calls this "soft skills" [6].

To minimize losses in the transmission of information, its manufacturers use not continuous, but discrete signal, which ensures clarity of the transmitted object contour down to every smallest detail. But there are no guarantees that deformations of the broadcast integrity, replaced by (clogged) disinformation, do not occur along the way. The procedure is as follows: the transmitted gestalt is first crushed into smallest parts, and immediately before the demonstration is assembled. In intermediate technological stages, distortion of the original content is not excluded.

This is the breeding ground for consciousness processing. Photomontage is, as they say, pitiful "blossom" in comparison with the "berries" of modern technologies.

They are convenient for any manipulation of meanings and images: from you then Photoshop to identifying meanness and mobility, theft and the ability to live, freedom and slavery. The digital copy is clearer than the original, but it is redundant, often negatively redundant. It atomizes the displayed item.

According to Stephen King, the Internet is the biggest keyhole in human history. The one who first called the Internet the global web hit the nail on the head. People hang out in this web like flies. It does not contribute to the development of antidote for bad taste and information junk.

Neurophysiologist, Baroness Greenfield states that "in 1999 people wrote in Livejournal that they had a cat, in 2004 they posted photos and videos of a cat, in 2010 they can tweet once an hour that their cat sneezed. Most users start telling each other that no one needs to know. They do it because they have such an opportunity" [10].

Greenfield draws attention to the virtualist's addiction to actions that do not have irreversible consequences, are repeatedly and easily replayed, so there is a habit of not being seriously responsible for the decisions made [10]. The emancipatory power of the Internet has the opposite effect. The declared freedom turns out to be lightweight, crude, semi-anonymous and irresponsible.

The Internet is convenient for the real possibility of provocations on the part of irresponsible cynics who consider themselves to be "civil society". The government responds to such guardians of "civil society" with total surveillance, in which any pseudonyms will be definitely disclosed and blocked.

The irony is that those who consider themselves to be out of control are in fact not excluded from the sphere of total control. Fashionable innovative technologies require automated category of managers: not strategists, but tacticians who are capable of adjusting all and everything to the ministerial criteria for assessing the activities of all educational institutions: higher, school, preschool.

The toolkit that dominates in ministerial instructions presupposes a set of certain professional qualities. Digital dementia is a scientifically proven fact of modern management. The deformation of the management corps (some authors call it more harshly pathology) is caused, according to psychiatrist Spitzer, by the increasing dependence of people on high-tech gadgets.

According to his research, the disease manifests itself in a general decrease in mental performance, loss of some elementary thinking skills, inability to critically evaluate facts, in a tendency to superficial knowledge (how is important, but not why), inability or loss of orientation in the flow of information, moreover, problems with personal identification [11].

\subsection{Arguments for Education Digitalization}

Actually, the arguments in favor of education digitalization are dictated by life itself and the speed of the changes taking place. The "digital society" is referred to in scientific literature as the next phase in the development of civilization and is characterized by the change in social structure and social interaction as a result of the widespread dissemination of innovative technologies. The basis of digitalization is technologies that allow typifying and converting analog data into digital, which theoretically makes it possible to transform all knowledge and even being into bits and bytes. With the increase in online access to fast broadband connections, more people are able to transfer digital data from personal media.

The volume of data and the number of users is growing exponentially. At the same time, the large volume of all kinds of information stimulates the development of high-tech carriers and repeaters. The digital environment functions as universal media platform for every taste. This affects all types of human life activity. As a result, "digitalization is becoming a universal driving force of society, and hence of education" [12].

These influences change of skills of today's students. So, before the digital age, it was important to 
develop a neat and legible handwriting. Currently, people write by hand very little. There is no need to memorize specific facts, they are easy to find on the Internet. And the study itself is no longer necessarily associated with educational institutions, because thanks to the Internet, it becomes possible to study outside the educational institution.

According to Professor Vorokhobov: "digital education significantly increases the motivation for learning, since there is always the necessary data, and the educational processes acquire new qualities, as students receive educational services in line with their own life context" [12].

Probably the scientist is right about the motivation for learning. However, it seems that the motivation for learning depends to a great extent on other reasons, in particular, the prestige of education, dependence on education more than on other factors, success in a career and in life in general. In the Soviet Union, for example, there was a cult of education and especially higher education. Soviet citizens with higher education wore on the lapel of their jacket a blue diamond-shaped pin button on higher education as a sign of higher honor.

\subsection{What Unites Supporters and Opponents of Education Digitalization?}

The positions of scientists agree that digitalization implies the change in the requirements for education: the requirements for teachers and the "infrastructure" of education are changing. Continuous diagnostics of software or personnel management is required. Digital media offers many options for educational programs, while retaining the universality features.

The variety of teaching methods is enormous nowadays, for example training videos. Massive Open Online Courses are gaining popularity. This term refers to free thematic courses online, usually involving renowned scientists. The combination of virtual and real learning allows people to transfer knowledge both directly and indirectly.

The distinctive feature of such training is that we can take advantage of these methods and avoid their disadvantages. Digital learning allows us to exchange roles with other learners and with the teacher during presentation events. Digitalization allows the student to create a kind of "virtual table" by himself. Digitalization makes it possible to enrich the perception of information.

Thus, the history of the Moscow Kremlin can be studied by "walking" around it virtually using QR code photo. Many digital programs include forms of collaboration. Game simulations reproduce real-life situations. For example, Toffler fears a potential "future shock" associated with disorientation and alienation. The very theory of disorientation and alienation arose as a result of excessive social and technological changes that a person is unable to realize and predict [13].

Kaplan put forward the idea of lagging (obsolescence) of intellectual work [14]. Education is associated with social and individual progress. Educational institutions, like all social infrastructure, are trying to comply with the changes. But the mismatch between reality and its conceptual perception is growing. In some sense, this is even a new law of dialectics.

Scientific reflection on understanding digital education is insufficient. There is assumption that the technological tools for achieving the goal are neutral in relation to the goal. The tools themselves are free from moral obligations and social values. The similar instrumental concept of technology was substantiated by Heidegger [15]. Many legal and pedagogical innovations assume that technology is ethically neutral.

However, new developments in the field of computation and information philosophy began to move away from this tradition and philosophically substantiate the social (ideological) component of digital tools [16].

Vorokhobov writes: "Where technology becomes questionable in principle, it is accused of arrogance, determinism or nihilism. Generalized suspicion that something is technologically advanced is as useless as a thoughtless assumption that technology is unambiguously positive. This type of polarization is enhanced by the range of binaries: natural versus artificial, organic versus synthetic, manifested versus imaginary" [12, 223 p.].

Polarization limits understanding of the complex nature of technological change. Now students can really do without educational institutions. Although the multitude of opportunities in itself does not mean improvement in education and its high quality.

With the growth of massive open online courses and the influence of technology on education, the problem of timely technological reflection on education and the cultural environment in general arises. The wide range of perspectives increases the responsibility of teachers, keeps them in suspense, which is reflected in the psyche of teachers. All the new requirements for teachers, a lot of paperwork, more precisely, now electronic files that teachers must fill out, depress their emotional tone, accumulate increased anxiety up to irreversible depressive neuroses. 
Educational technologies also affect students. The assignment of education to the service sector and its "cleansing" from the function of upbringing, which began in Russia in the 1990s, caused irreparable harm to both education and society in general.

With regard to the above, the well-known and authoritative Russian philosopher Ilyin wrote in one of his publicist articles at the beginning of the twentieth century: "Education without upbringing does not form a person, but unbridles and spoils him/her, because it gives him/her vital opportunities, technical skills, which he/she, being spiritless, shameless, faithless and characterless begins to abuse" [17]. The description is so up-to-date as if it was written yesterday.

\section{CONCLUSIONS}

All in all, digital education made a revolution in teaching and learning. The educational process has undergone changes due to distance learning using digital devices. However, social, ethical and other problems that accompany these changes are not predicted sufficiently.

The changes that took place mean substantial and methodical transformations. Virtualization of education at the moment is the quintessence of part-time education and self-education, which is due to the rapid development of telecommunication systems and multimedia technologies, as well as the mobility of network communication.

The changes that took place naturally cause fierce disputes among scientists, politicians, public figures, and the entire civil society.

Ultimately, the arbiter of all disputes around education is the state, on which it depends on which way education will develop. The state is responsible for the quality of education. In the 50-60s of XX century, the Soviet Union came out on top in the world in terms of the quality of education. The following fact is well known. After the flight of Gagarin, Kennedy requested to make the study to answer the question of why the USSR overtook the United States in space achievements. The multi-page study ended with the conclusion: The Soviet Union has cult of education.

Now, according to the same criteria, Russia is only in the middle of the list of states. This sad result has been interpreted differently by scientists. And the attitude of scientists to digital and distance education is different. However, no country has a future without the state program and ideology of education.

\section{REFERENCES}

[1] N.A. Bobrova, V.N. Sidorov, Leading Provisions of the Digitalization, Law, Science (2020), in: Proceedings of the 6th International Conference on Social, economic, and academic leadership, Series: Advances in Social Science, Education and Humanities Research (ICSEAL-6-2019), Atlantis Press, Paris, 2020, pp. 317222. DOI: https://doi.org/10.2991/assehr.k.200526.046

[2] N.A. Bobrova, Devaluation of legal education: general theoretical analysis, Education and law 8 (2018) $179-181$

[3] A.N. Tarasova, E.N. Korneeva, R.K. Krayneva, S.A. Gudkova, Pitfalls and Itfalls and Drawbacks in Engineering Education in Russia, Journal of Applied Engineering Science 17(1) (2019) 43-51. DOI: https://doi.org/10.5937/jaes17-19097

[4] E.V. Kirichek, Digitalization of the constitutional and legal, social and political life in modern Russia: positive and negative aspects, Legal Science and Law Enforcement Practice 3(53) (2020) 33-40.

[5] N.A. Bobrova, Digitalization: pros and cons, Constitutional and municipal law 10 (2019) 23-25.

[6] TASS (2020) H. Gref: I'm a long-time player. Head of Sberbank russia - in the special project "First Persons of Business", Part 1. https://tass.ru/businessofficials/8827375 Accessed on 21 Jan 2021

[7] KINO-TEATR.RU (2020) N. Mikhalkov says H. Gref's project will destroy traditional education. https://www.kino-teatr.ru/lifestyle/news/y2020/610/21467/ Accessed on 11 Jan 2021

[8] DonNU (2019) N. Mikhalkov: "Will Google break the spire of http://news.donnu.ru/2019/02/06/slomaet-li-googleshpil-mgu-avtorskij-vzglyad-nikity-mihalkova-naproblemy-sovremennogo-obrazovaniya/ Accessed 10 Jan 2021

[9] A.N. Fatenkov, With digital technology - into an inhumane future, Bulletin of the Nizhny Novgorod Academy of the Russian Interior Ministry 1(49) (2020) 218-221.

[10] Theory\&Practice (2020) S. Greenfield, Interview "A child brought up on social media loses his ability to empathize") https://theoryandpractice.ru/posts/3539syuzan-grinfild-rebenok-vospitannyyna-sotsialnykhsetyakh-teryaet-sposobnost-k-soperezhivaniyu Accessed 01 Nov 2020

[11] M. Spitzer, Anti-brain: digital technology and the brain, AST, 2014, 284 p. 
[12] A.V. Vorokhobov, Digitalization of education: current trends and philosophical and methodological problems, Bulletin of the Nizhny Novgorod Academy of the Russian Interior Ministry 1(49) (2020) 220-223.

[13] E. Toffler, The shock of the future, AST, 2002, $557 \mathrm{p}$.

[14] J. Kaplan, Humans need not apply: A guide to wealth and work in the age of artificial intelligence, Yale University Press, 2015, 256 p.

[15] M. Heidegger, The question of technology, Republic, 1993, pp. 121-137.

[16] D. Lundie, The givenness of the human learning experience and its incompatibility with information analytics, Educational Philosophy and Theory, 2015, pp. 1-14.

[17] I.A. Ilyin, On education and education in the future Russia, The importance of faith in pedagogy, Amrita, 2018, 224 p. 